\section{Dificultades de acceso al aborto en contextos de interrupción legal del embarazo: narrativa de estudiantes de bachillerato en una comunidad campesina de México}

\author{
Difficulties accessing abortion in legal termination \\ contexts: high school students' narratives in a \\ rural community in Mexico
}

Dificuldades de acesso ao aborto em contextos de interrupção legal da gravidez: narrativa de estudantes do Ensino Médio em uma comunidade rural do México

\section{Resumen}

En este trabajo se analizan las creencias y prácticas entre jóvenes estudiantes de bachillerato que buscan o consideran la posibilidad de interrumpir un embarazo. Se eligieron estudiantes de una escuela pública situada en un una comunidad rural y campesina de la Ciudad de México, México. Es un estudio etnográfico de corte constructivista, basado en entrevistas en profundidad a 15 mujeres de entre 18 y 24 años de edad, con vida sexual activa. Las entrevistas fueron grabadas con autorización y bajo el consentimiento informado de los participantes. Los hallazgos indican que persisten estigmas sociales que afectan la dignidad de las mujeres que eligen abortar. Sin embargo, las ideologías católicas no parecen ser persuasivas para que las informantes decidan continuar con un embarazo que no desean. En todo caso, la falta de confidencia en las clínicas puede llevar a las jóvenes a optar por espacios clandestinos o a la automedicación, generalmente basada en herbolaria y pastillas abortivas. Llama la atención que las informantes reconocieron que no usaban preservativos y que eventualmente emplean anticonceptivos orales. Los sistemas de salud públicos en la comunidad no siempre garantizan la confidencialidad para interrumpir legalmente un embarazo, por eso no son contemplados por las jóvenes entrevistadas como la primera opción para suspender la gestación. Por otro lado, es muy necesaria la consolidación de proyectos educativos en sexualidad que permitan a las jóvenes evitar embarazos que no desean y puedan ejercer plenamente sus derechos sexuales y reproductivos. Además, es importante incluir acciones relativas a la sensibilización y capacitación de profesionales de las instituciones de enseñanza.

Aborto; Sexualidad; Mujeres; Estudiantes
Daniel Hernández-Rosete 1

Rocío Estrada-Hipólito 1

doi: $10.1590 / 0102-311 \times 00046218$

Correspondencia

D. Hernández-Rosete

Departamento de Investigaciones Educativas, Centro de Investigación y de Estudios Avanzados.

Calz. Tenorios 235, Col. Granjas Coapa, Ciudad de México 14330, México.

danielshr204@yahoo.com.mx

1 Departamento de Investigaciones Educativas, Centro de Investigación y de Estudios Avanzados, Ciudad de México, México. 


\section{Introducción}

Con excepción de la Ciudad de México, en el resto del país la interrupción inducida del embarazo sólo es legal en casos de violación sexual 1,2 y persiste su criminalización cuando obedece a otras causas. Por ejemplo, el riesgo de muerte para la mujer en gestación o la existencia de malformaciones genéticas en el feto, aún son causas restringidas legalmente, y la sanción depende del Código Penal de la entidad federativa en donde ocurre. Una consecuencia grave de esta prohibición es que el aborto -sólo permitido en casos de violación- afecta la dignidad de la mujer, pues la experiencia de haber sido violada también es una causa de estigmatización.

A pesar de su penalización, el 54\% de los embarazos no deseados son suspendidos en condiciones de pobreza y clandestinidad 3 . Se trata de un problema de salud pública que agudiza las desigualdades, pues cuando la práctica clandestina del aborto es insegura afecta especialmente a las mujeres con menores recursos educativos, monetarios y legales 4. Otro ejemplo de esta polarización es que, en la mayoría de los estados en México y en algunas regiones de Latinoamérica, cuanto mayor sea el capital educativo de la mujer en el momento de practicar un aborto, mayor es la calidad de servicios de salud, y es menos probable que enfrente situaciones de maltrato 5 . Por el contrario, las mujeres más pobres y con menor capital social y económico no siempre logran interrumpir un embarazo que no desean 6 . Pero si lo logran, lo hacen en condiciones que ponen en riesgo su capacidad reproductiva y pueden llegar a ser violentadas en su dignidad, porque son consideradas como no dignas para la maternidad 7 .

En el caso específico de la Ciudad de México, el embarazo se puede interrumpir legalmente durante las primeras doce semanas de gestación. Esta condición jurídica existe desde abril de 2007, y no sólo contempla las causas mencionadas, además considera la voluntad de las mujeres como criterio suficiente. Hasta febrero de 2018 se habían practicado 191.356 abortos 8, esta cifra cobra sentido al considerar que la interrupción legal del embrazo ofrece condiciones de seguridad hospitalarias que protegen la salud reproductiva de las mujeres al abortar. Además, promueve el respeto de sus derechos humanos, pues se ha documentado la existencia de formas de violencia obstétrica que ocurren cuando las mujeres asisten a salas de urgencia por complicación de aborto 9 .

Sin embargo, la interrupción legal del embrazo no necesariamente se practica al margen de estigmas sociales 10,11, pues entre algunos sectores de población persisten creencias que cuestionan moralmente el ejercicio de este derecho reproductivo 12 . Entre los principales argumentos se advierten ideas religiosas sobre fecundación 4,13, y tienen tal peso que surge una paradoja histórica entre la despenalización jurídica del aborto y la notable vigencia de su prohibición moral. Se ha documentado, por ejemplo, la fuerte influencia de los discursos católicos en la decisión de llevar a término embarazos no deseados 14 , incluso como práctica médica 9,15. Esto se relaciona con la idea de que la vida humana se inicia con la fecundación, lo que refuerza el principio teológico del derecho a la vida humana de un cigoto, o incluso de un embrión, que aún no adquiere la madurez fetal 16.

Esta argumentación deviene en discurso político ${ }^{5}$ y resulta especialmente eficiente en zonas conservadoras 17 , sin embargo, también llegó a impactar en la Ciudad de México pues, en sus inicios, la interrupción legal del embrazo fue puesta en duda por algunos médicos que se negaron, por objeción de conciencia, a practicar las interrupciones si se trataba de casos en que la mujer no demostraba tener motivos "legítimos", como la violación o las malformaciones genéticas en el feto 18 . En estos casos se vuelve polémico el papel de los médicos por su condición de servidores públicos en un Estado presuntamente laico.

Pese a la notable coerción social que sanciona el aborto con base en argumentos religiosos, la evidencia empírica sugiere que las mujeres católicas pueden optar por el aborto y de hecho lo practican, pues se sabe que cerca del sesenta por ciento de las usuarias de servicios de la interrupción legal del embrazo en la Ciudad de México son personas de origen católico, que decidieron suspender sus embarazos, al asumir que este ya no representa un delito 19 .

Pero la interrupción legal del embrazo parece que no siempre es suficiente para garantizar un aborto seguro 20,21,22, por eso, resulta de interés antropológico señalar que aún son escasos los estudios que describen las dificultades, que enfrentan las mujeres jóvenes en la Ciudad de México, para interrumpir legalmente un embarazo. Esto define el interés del presente estudio, pues nos proponemos describir las dificultades para acceder a la interrupción legal del embrazo, narradas por jóvenes 
estudiantes de un bachillerato, ubicado en una zona agrícola de la Ciudad de México. Especialmente, analizamos algunas de las creencias católicas sobre gestación, pues consideramos que pueden tener relación con la decisión de llevarlo a término.

\section{Método}

Estudio etnográfico de tipo fenomenológico 23 , con el que se exploraron universos de sentido y significado, a través de entrevistas semiestructuradas con mujeres que enfrentan la posibilidad de interrumpir un embarazo. Reconocemos que la interrupción legal del embrazo implica entramados de significado que existen en contextos de relaciones de poder asimétricas 24 , es decir, las narraciones recabadas expresan creencias inherentes a los estereotipos de género y a los valores católicos que rigen la vida familiar y otros ámbitos sociales, pero también dan cuenta de las dudas que tienen las personas entrevistadas, al saberse con derechos sexuales y reproductivos, por lo que sus prácticas sociales no siempre coinciden con los mandatos sociales de tipo religioso. En ese sentido, nos pareció importante asumir que las personas son agentes reflexivos 25 , porque al ser conscientes de la realidad, son susceptibles de asumir cierta agencia al actuar. De modo que abrimos el margen de exploración, tomando en cuenta la posibilidad de que las informantes podían mostrar inquietudes, y cuestionar los mandatos sociales que rigen sus creencias católicas sobre vida sexual activa y reproducción.

Se elaboró un diario de campo para describir aspectos de la vida cotidiana estudiantil en distintos contextos, como el salón de clase, las canchas, los patios y los baños de la institución, así como en sus alrededores y en espacios lúdicos y de esparcimiento fuera del contexto escolar.

\section{Universo de estudio y trabajo de campo}

Entre agosto de 2012 y diciembre de 2013 se entrevistaron en profundidad a 15 mujeres, de entre 18 y 24 años de edad, con vida sexual activa e inscritas en el bachillerato del pueblo. Fundamentalmente, se recogieron datos que ayudan a conocer sus opiniones sobre la interrupción del embarazo y se hizo énfasis en la forma en que asumen determinadas posturas, como resultado de un conflicto entre las reglas socialmente aceptadas y la significación personal del aborto. Para las jóvenes que participaron en el estudio, la instalación de un bachillerato público en la región ha posibilitado la reinserción en el sistema educativo. Por esta razón, sus edades salen del rango regular de la educación media superior y son, en su totalidad, personas con edades entre 18 y los 24 años. Trece de las mujeres nacieron en la Ciudad de México y las restantes son migrantes provenientes de Oaxaca y Guerrero.

Todas las informantes eran mayores de edad cuando participaron en el estudio, sin embargo, algunas de las narrativas dan cuenta de los dilemas que enfrentaron cuando aún no eran adultas. Además, las entrevistas son el resultado de una larga convivencia con las informantes, dentro y fuera de las instalaciones educativas del bachillerato en cuestión, de modo que las jóvenes fueron informadas del objetivo del estudio, y sólo se entrevistó a las que aceptaron participar de manera voluntaria. Es importante destacar que las entrevistas fueron grabadas con el consentimiento informado de las participantes y bajo el acuerdo de que se sus narraciones serían anónimas y confidenciales. Así, las entrevistas se llevaron a cabo individualmente y de manera privada en una sala proporcionada por las autoridades educativas.

El trabajo de campo se desarrolló en una comunidad agrícola con un notable arraigo al cultivo del maíz en el sur de la Ciudad de México 26. Se trata de una alcaldía considerada como semirrural y está considerada como el municipio en donde más se usa carbón y leña como combustible para cocinar 27. Además, el $40 \%$ de las viviendas no tiene acceso a agua entubada y tiene pisos de tierra. Cabe destacar que, dentro de la ciudad, es la demarcación en donde se registra el mayor porcentaje de personas que se reconocen como hablantes de una lengua indígena 27. En materia de educación, esta comunidad tiene la mayor tasa de analfabetismo en la población de 15 años y más, y el menor promedio de escolaridad en las personas en el mismo rango de edad 27. Además, presenta la mayor proporción de embarazos adolescentes, respecto al total de nacimientos registrados en la demarcación (21,8\%), y por varios años ha mantenido el récord en el porcentaje de nacimientos registrados de madres entre los 12 y los 19 años de edad 28 . 


\section{Resultados}

\section{Entre el erotismo y la culpa}

Diversos autores 29,30 coinciden al señalar que el placer sensual se perfila como uno de los tabúes más sancionados por la iglesia católica. Esto tiene relación con el control de la reproducción humana, pues la sexualidad católica históricamente ha contrapuesto la reproducción al placer erótico 31. Nuestro estudio da cuenta de la vigencia de estos mandatos teológicos, pues entre las informantes la vida sexual activa ocurre como un proceso cargado de culpa. Creemos que se trata de una dinámica que hace que las jóvenes entrevistadas sean vigilantes de sus actos a través de una dimensión atormentada de la sexualidad. Un aspecto antropológico que llamó nuestra atención es que esta vigilancia entre jóvenes atenta contra el libre albedrío, uno de los elementos fundamentales en la autonomía en materia de vida sexual activa 29 . Si bien las informantes no asumen explícitamente la visión católica en sus narrativas, es evidente que aún se apegan a ellas. Por ejemplo, persiste la creencia de que la vida humana surge desde la unión del óvulo con el espermatozoide: “...ya en el primer instante en que el esperma toca el óvulo, ya empezó una nueva vida. Es que muchas personas dicen que no, que todavía ni a feto llega. Pero ya es algo que empieza a tener vida desde ese mismo momento, ya es alguien, no es algo, es alguien. Si yo la llego a regar en alguna relación sexual no me gustaría abortar a ese pequeño ser" (Estudiante mujer, 19 años, tercer semestre de bachillerato, nunca ha estado embarazada).

Esta representación judeocristiana coexiste con niveles de formación laica propios de la educación media superior. Por eso, llama la atención que en su testimonio esta joven atribuya al cigoto el estatus de persona pero, paradójicamente, excluya a la figura de la mujer embarazada como sujeto de derecho 32 . Es un sistema de creencias que está presente en el pensamiento de nuestras informantes, quienes dijeron estar dispuestas a llevar a término un embarazo, aun cuando no desean ser madres.

También les preocupa el escarnio social que suscita un embarazo cuando este es consecuencia de prácticas sexuales fuera del matrimonio. Es decir, al parecer temen más al estigma que se atribuye a una mujer joven que aborta, que al mandato religioso ligado a la prohibición del aborto.

En las narrativas, la interrupción del embarazo se asocia a la supuesta maldad de quien contraviene la moral cristiana, particularmente el mandato de no matar. Así lo deja ver una joven que considera al aborto como un hecho equiparable al homicidio: “...ponle que aborte, y tiene un proyecto de vida, pero después de abortar, pues lógicamente las consecuencias tienen que llegar tarde o temprano ¿no? Pues el remordimiento de lo que hizo, no sé, el trauma psicológico de haberlo hecho, de haber terminado con una vida" (Estudiante mujer, 21 años, quinto semestre de bachillerato, nunca ha estado embarazada).

La decisión de interrumpir un embarazo implica la angustia atribuible al presunto asesinato. Sin embargo, hay una contradicción, porque en medio de este entramado existen también prácticas sexuales sin protección, pues las informantes reconocieron que no siempre usan preservativo y que eventualmente emplean anticonceptivos orales. Desde esta óptica parece que tener un hijo es un mandato inherente a la vida sexual activa, pero además corroboramos que hay poca reflexión sobre lo que implica la crianza, como apuntan otros estudios 33 .

“- ¿Tú interrumpirias un embarazo?

- No, porque de todas maneras ya está hecho y no me gustaría sentirme culpable.

- ¿Culpable de qué?

- Bueno, de sacar al bebé. Me sentiría yo culpable, preferiría tenerlo" (Estudiante mujer, 19 años, tercer semestre de bachillerato, nunca ha estado embarazada).

De hecho, para algunas de ellas la culpa atribuible al aborto no necesariamente inhibe la intención de tener relaciones sexuales sin protección, además es claro que existe una vigilancia entre mujeres, siempre desde una dimensión culposa que afecta la dignidad e inhibe la conciencia sobre libre albedrío, necesario para reconocerse como ciudadanas con derechos sexuales y reproductivos.

\section{Prejuicios religiosos en una institución laica}

Encontramos que en el bachillerato hay personal médico que profesa creencias católicas y ofrecen información incorrecta a los alumnos, especialmente cuando preguntan sobre la interrupción del 
embarazo. Una estudiante relata lo que sucedió cuando sospechó estar embarazada y pidió información sobre aborto a personal médico del bachillerato.

"La doctora del plantel me dijo: '- es que no es nada más abortar porque no lo quiero. El aborto tiene sus implicaciones, tú ahorita te puedes tomar una pastilla y una inyección y todo eso, pero a veces esos medicamentos hacen que se salga el producto, pero también te desangras. O la matriz se afecta demasiado y ya no puedes tener hijos después.' Fue por eso que tuve miedo de abortar. Me contó también que una chica, que había abortado, se desangró. Había utilizado unas yerbas que se usan para abortar. Se había pasado de dosis y pues se desangró. Después ya habia quedado estéril. Otra chica fue a un lugar para que abortara y pues igual, le afectaron la matriz, no sé qué le hicieron, pues casi todo se le salió, el feto igual pero también parte de la matriz y no sé qué tanto le habian quitado. Entonces, por eso, sí me metió como que miedo" (Estudiante mujer, 19 años, sexto semestre de bachillerato, nunca ha estado embarazada).

La asesoría no necesariamente ofreció información cualificada, pues la doctora tergiversó las condiciones reales en que se realiza la interrupción legal del embarazo en la Ciudad de México. Pareciera que pretende generar miedo, y así reglar la actividad sexual y reproductiva de las jóvenes, pues asume posturas morales que olvidan la visión laica que deben ofrecer las instituciones de educación pública en nuestro país. En este caso, parece que el principal objetivo es que la alumna desista de una interrupción del embarazo, a través del miedo a una complicación obstétrica como la esterilidad, que, por cierto, aparece en la descripción como un castigo merecido. El relato denota faltas éticas en el ejercicio de la profesión médica, sobre todo si se toma en cuenta que las estudiantes ven a la doctora como una figura autorizada para opinar al respecto.

Otros alumnos refieren que en una clase se les mostró un vídeo donde se practicaba un aborto y sacaban del útero a un feto en partes. Este relato se encontró en varios informantes y parece estar ligado a campañas de grupos pro-vida 12, quienes han usado vídeos que muestran el desmembramiento de un feto en un desarrollo avanzado. La imagen no corresponde a la etapa fetal legalmente permitida para realizar la interrupción legal del embarazo. En cambio, sí genera un rechazo al aborto dentro de las primeras 12 semanas de gestación.

“- ...la otra vez vi un vídeo de cuando estaban despedazando a un bebé y, sí, se siente horrible ¿no?, yo creo que hacer eso con un bebecito creo que no.

- ¿En dónde viste ese vídeo?

- Aquí en la escuela" (Estudiante mujer, 24 años, cuarto semestre de bachillerato con posible embarazo).

La conformación ideológica del personal médico de este bachillerato no siempre se apega a la educación laica, pues propagan ideas religiosas sobre aborto. Esto es muy delicado, ya que genera prejuicios morales que impiden a las estudiantes tomar decisiones apegadas a marcos éticos y de información cualificada sobre el aborto.

\section{Clandestinidad dentro de la legalidad}

Para Palomar \& Suárez 34, la maternidad es una construcción social y consiste en naturalizar un proceso reproductivo, haciéndolo pasar como un hecho instintivo. El fenómeno es tan potente que incide negativamente en la imagen de aquellas mujeres que no cumplan con esta normativa, de tal forma que pueden ser catalogadas como anormales, enfermas o desviadas 34 . Nuestra investigación sugiere que esta idea se encuentra tan arraigada entre las informantes, que tener un hijo da sentido a la unión conyugal, pero además aparece como condición existencial, incluso cuando una mujer no tiene pareja. Por ejemplo, en la casa de una mayordoma escuchamos decir que cuando una mujer está en edad de tener hijos y sin pareja debe embazarse para que su hijo la cuide cuando ella sea vieja. Para ese fin, se prefiere que sea una hija, porque a ella se le tendrá más confianza. Ambas son formas de presionar el inicio de la maternidad de las personas en etapas muy tempranas de edad reproductiva. Particularmente, se hace más evidente en jóvenes en edad de terminar la secundaria y/o iniciar el bachillerato; entre los quince y diecinueve años aproximadamente.

Las jóvenes creen que el estigma del aborto puede comenzar con el juicio moral por parte de los médicos y la violación de su derecho a la confidencialidad.

“- No me gustaría que se enteren los demás.

- ¿Qué sentirías si se enteraran los demás? 
- Pues a lo mejor como pena y a la vez como enojo de que anden publicando mis cosas. O sea, que el doctor le diga a otro doctor '- oye, ¿y a esta paciente qué le pasó? -Es que fíjate que así y asado- - Pues, ¿no nada más lo puede saber uno, sino lo tienen que saber miles?' O sea, como que no, y ya ves que uno le cuenta a otro y así.

- ¿Qué crees que piensen de una chava que interrumpe su embarazo?

- Que a lo mejor no tiene corazón ¿no?” (Estudiante mujer, 24 años, cuarto semestre de bachillerato con posible embarazo).

Esto ayuda a comprender por qué algunas de las mujeres que querían interrumpir su embarazo deben realizarlo de manera clandestina. Es decir, no siempre pueden acudir libremente a los servicios médicos, pues saben que en caso de que su decisión se haga pública, serán objeto de reprimendas y estigmas, ya que socialmente no está permitido que una mujer rechace su embarazo. Creemos, por eso, que el embarazo aún funciona como una forma de control social sobre el cuerpo y el erotismo de las mujeres, ya que persiste la idea de que ser madre es la única razón que justifica que una mujer ejerza su sexualidad.

Es paradójico que al acceder a los servicios médicos para solicitar una interrupción del embarazo, aunque sea un derecho, se experimente el riesgo de invasión a la privacidad. Por eso, al buscar remedios tradicionales, como la ingesta de un té abortivo, se logra mayor discreción. Es decir, el acceso a la herbolaria abortiva, vinculado a su clandestinidad, ofrece privacidad, pues quien proporciona el brebaje también necesita resguardar su identidad por temor a las represalias.

Intentando evadir la estigmatización, o el cuestionamiento por parte de los familiares, una joven narró que antes de buscar ayuda en una clínica del sector salud recurriría a la herbolaria y asume que sólo acudiría al doctor si el riesgo de muerte fuera inminente.

"- ¿Te da miedo que se entere tu familia?

- Pues sí, porque me dirían: '- ¡Ay!, ya tienes una niña de otro hombre y ahorita vas a tener un bebé y luego quién es el papá del niño'. O sea, aunque yo no les diga van a decir -es que no, cómo otro niño sin papá.

- ¿Y qué tal si te desangras mucho por tomarte el té o la pastilla?

- Pues entonces, sí, iría al doctor.

- Pero se enterarían los doctores y tu familia.

- Pues ya ni modo.

- Pero si lo que quieres es que no se enteren.

- Pues ni modo, ahora sí, que como dicen -o tu vida o que rumoree todo el mundo" (Estudiante mujer, 24 años, cuarto semestre de bachillerato, con posible embarazo).

En la medida de sus posibilidades, esta joven buscaría interrumpir un embarazo clandestinamente, pues parece preocuparle mucho que su aborto se convierta en un asunto público. Esto resulta particularmente complejo, pues concibe al aborto como un derecho sólo si se garantiza la confidencialidad de su decisión. Por eso, es preocupante que el derecho a la interrupción legal del embarazo coexista con prácticas de clandestinidad, particularmente entre jóvenes que lo reconocen como un legítimo derecho, pero que por faltas en el proceso de confidencialidad deciden renunciar a este.

\section{El retraso en la decisión}

A pesar de que las jóvenes entrevistadas saben que en la Ciudad de México pueden interrumpir legalmente el embarazo, no siempre acuden a los servicios públicos de salud como su primera opción. Una estudiante narró una experiencia ocurrida cuando era menor de edad, nos explicó que con cuatro meses de gestación entre sus planes no estaba ser madre en ese momento. Decía que la asistencia al bachillerato se lo imposibilitaría, pues era prioritaria su formación académica. Sus padres también querían que ella estudiara. Como en otras ocasiones que sospechaba estar embarazada, ella tomó la pastilla de emergencia, pero esa vez no fue efectiva.

El primer mes de gestación no tenía la certeza de estar embarazada. Este lapso transcurrió esperando la menstruación y juntando el dinero para comprar una prueba de embarazo. Tardó cerca de un mes en conseguir el dinero para hacerse una prueba rápida y enterarse que estaba embarazada, de modo que para el segundo mes emprendió la búsqueda de alguien que supiera de herbolaria y le ayudara a provocar un aborto. Sin embargo, no pudo contactar a nadie.

Aunque sabía que la interrupción del embarazo era legal, se enfrentó a la falta de información, pues creía que en el servicio particular podría prescindir de la responsiva firmada por un adulto. 
Por otro lado, de haber asistido a los servicios públicos de salud tendría que haber contado con la aprobación de su madre o de algún adulto, debido a su condición de menor de edad. Y como era de esperarse, no quería que su madre supiera de su embarazo. Por lo tanto, el proceso a seguir implicaba la clandestinidad.

Cuando pasó del segundo mes, y no encontró a quien preparaba los brebajes, buscó en Internet y supo de un té que era muy efectivo y disponible a la venta en cualquier mercado. Lo consumió, pero tampoco le hizo efecto. Posteriormente, le dijo a su pareja que tenían que conseguir el dinero, porque la única opción era acudir a un servicio médico privado y clandestino. Cuando juntaron el dinero ya habían pasado más de tres meses, que es el periodo en que está permitida la interrupción legal del embarazo. A la joven, quien además ya no podía esconder más su embarazo, no le quedó más que llevarlo a término.

Esta historia es una expresión de injusticia social y mucho tiene que ver la legislación vigente sobre interrupción legal del embarazo, pues no se contempló lo necesario para que las usuarias que aún no alcanzan la edad legal pudieran ejercer de manera autónoma la interrupción del embarazo, pues para acceder al servicio se necesita la firma de un adulto. Por eso, algunas interrupciones se siguen realizando clandestinamente con todo lo que puede implicar: riesgos para la salud, riesgos penales, culpa y el miedo al estigma si se descubre.

Como sostiene Erviti 4 , las redes sociales de apoyo con que cuentan las mujeres son determinantes en la forma de practicar y procesar un aborto, pero, además, la dependencia moral y económica es decisiva, pues al no contar con recursos financieros y la confianza necesaria para que un adulto firme como responsable de la intervención médica, no pueden acceder a la interrupción legal del embarazo.

Aquí se observa que las condiciones que se exigen para acceder a los servicios médicos no concuerdan con las necesidades y condiciones de algunas usuarias jóvenes menores de edad. Las inconsistencias legales para que una joven en edad reproductiva pueda acceder a la interrupción legal del embarazo pueden poner en riesgo la salud sexual y reproductiva de las jóvenes menores de dieciocho años. Suponemos que se requiere un debate más amplio sobre la legalidad existente, a fin de incluir el derecho a la privacidad como recurso fundamental en el ejercicio de la interrupción legal del embarazo.

\section{Consideraciones finales}

En México la religiosidad católica aún parece inhibir el ejercicio de derechos sexuales, especialmente con relación al aborto. Sin embargo, en el contexto estudiado, la decisión para no suspender un embarazo no deseado está ligada a razones más complejas, pues las jóvenes creen que los servicios médicos de su localidad no respetan la privacidad y el anonimato. Y es que, en la comunidad estudiada, las relaciones de parentesco y de vecindad marcan la estructura social de los sistemas de salud, hasta el punto que el personal de las clínicas de salud suelen ser vecinos y parientes de otros miembros de la comunidad. Esto inhibe el acceso a una decisión libre y confidencial en torno al aborto, por eso, los servicios de salud públicos no son contemplados como espacios confiables para interrumpir un embarazo.

La falta de confidencialidad en los sistemas de salud locales puede obligar a que las mujeres que quieren abortar busquen otras opciones. Nuestras informantes parecen haber solicitado tratamientos de herbolaria con fines abortivos, porque están insertos en redes de clandestinidad que sí ofrecen confidencialidad y privacidad. Sin embargo, al recurrir a estos medios se genera un retraso importante en la línea de tiempo para solicitar atención médica, además, hay evidencia para considerar que las jóvenes sólo recurrirían a los servicios médicos públicos en casos de riesgo inminente de muerte. En este sentido, creemos que garantizar la privacidad es un derecho fundamental para poder preservar la vida y el derecho a la salud reproductiva.

Aunque las mujeres entrevistadas eran mayores de edad, algunas de sus narraciones dan cuenta de los dilemas que experimentaron cuando eran menores de edad. Lo que es notable es que no siempre contaron con las redes sociales, ni con los recursos jurídicos y económicos necesarios, para acceder a una interrupción legal del embarazo. Por eso, consideramos que la despenalización del aborto, tal como está planteada en la Ciudad de México, excluye a sectores de mujeres jóvenes menores de edad, 
quienes se ven impedidas para suspender, en condiciones de seguridad y dignidad, un embarazo que no desean. Esta situación puede tener consecuencias irreversibles en su salud reproductiva y mental, pues las prácticas abortivas clandestinas siguen siendo una opción para este grupo de población.

Por otro lado, detectamos que entre las informantes es común la práctica de relaciones sexuales sin condón y el uso de métodos anticonceptivos es prácticamente inexistente, de modo que si la joven se embaraza será socialmente coaccionada para que acepte una maternidad que no siempre desea y que parece ser un castigo meritorio por haber tenido vida sexual activa antes del matrimonio. Es decir, los embarazos llevados a término pueden ser expresiones cotidianas y naturalizadas de la maternidad, que aún es tenida como la forma de redimir la falta moral por haber tenido relaciones sexuales fuera del matrimonio.

No obstante, lo que resulta polémico, es que esta misma postura es asumida por el personal del bachillerato, frente a alumnas que sospechaban estar embarazadas y que contemplaban la interrupción. Así, los esfuerzos por ofrecer educación sexual laica, para que los sujetos puedan comprender sus derechos y tomar decisiones libres de prejuicios, en algunos casos se ven rebasadas por la influencia de las ideas de origen judeocristiano del personal médico del plantel.

Lo que hay que subrayar es que el conocimiento laico en materia de educación sexual no parece ser suficiente para contender exitosamente con las ideas religiosas, pues el miedo al estigma aparece como un mecanismo vigente para inhibir la práctica del aborto como derecho legal y como una práctica derivada del libre albedrío.

Consideramos, entonces, que las políticas públicas en materia de interrupción legal del embarazo deben garantizar que las jóvenes accedan al ejercicio de sus derechos sexuales en un contexto de pleno respeto a la privacidad y el anonimato. Finalmente, se advierten carencias importantes en materia de educación sexual laica y en el acceso a anticonceptivos, por eso creemos que, si bien la interrupción del embarazo ya existe como un derecho en la Ciudad de México, además es necesaria la consolidación de proyectos educativos que permitan a las jóvenes evitar embarazos que no desean y además tener acceso al goce pleno de la sexualidad.

La educación sexual laica es la contribución histórica más importante para desnaturalizar la maternidad como mandato social. Por eso consideramos necesaria la consolidación de proyectos educativos en materia de sexualidad, dirigidos especialmente a poblaciones juveniles, que no parecen haber asumido plenamente su condición de sujetos de derechos sexuales y reproductivos.

Asimismo, es importante crear espacios de capacitación y sensibilización sobre confidencialidad y derechos reproductivos, dirigidos al personal médico, psicológico y docente que trabaja con jóvenes, tanto en planteles escolares, como en centros de salud comunitarios. 


\section{Colaboradores}

D. Hernández-Rosete participó de la elaboración del protocolo de investigación, estructuración del manuscrito, análisis de entrevistas, redacción general del artículo, elaboración de conclusiones, introducción, planteamiento y hallazgos. R. Estrada-Hipólito colaboró em el trabajo de campo, transcripción de entrevistas, análisis de datos y escritura de parte del artículo.

\section{Informaciones adicionales}

ORCID: Daniel Hernández-Rosete (0000-00034030-2663); Rocío Estrada-Hipólito (0000-00020201-9464).

\section{Agradecimientos}

Agradecemos a las mujeres cuyos relatos nos permitieron comprender la complejidad del acceso a la salud reproductiva en la Ciudad de México.

\section{Referencias}

1. Sánchez F, Paine M, Elliott-Buettner B. The decriminalisation of abortion in Mexico City: how did abortion rights become a political priority? Gend Dev 2008; 16:345-60.

2. Ubaldi N. El proceso de despenalización del aborto en la Ciudad de México. México DF: Grupo de Información en Reproducción Elegida; 2008.

3. Juárez F, Singh S, Maddow-Zimet I, Wulf D. Embarazo no planeado y aborto inducido en México: causas y consecuencias. Nueva York: Guttmacher Institute; 2013.

4. Erviti J. El aborto entre mujeres pobres: sociología de la experiencia. Cuernavaca: Centro Regional de Investigaciones Multidiciplinarias, Universidad Nacional Atónoma de México; 2005.

5. Lamas M. El aborto en la agenda del desarrollo en América Latina. Perfiles Latinoamericanos 2008; 31:65-93.

6. Erviti J, Castro R, Collado A. Strategies used by low income Mexican women to deal with miscarriage and "spontaneous" abortion. Qual Health Res 2004; 14:1058-76.

7. Medor D. La producción de niños buenos y madres devotas en la fabricación de una nación. Desacatos 2014; 46:216-9.

8. Secretaría de Salud de la Ciudad de México. Interrupción legal del embarazo (ILE): estadísticas abril 2007 - 20 de abril de 2017. http:// ile.salud.cdmx.gob.mx/wp-content/uploads/ Interrupcion-Legal-del-Embarazo-Estadis ticas-2007-2017-20-de-abril-de-2017.pdf (accedido el 26/Feb/2018).

9. Erviti J, Castro R, Sosa I. Las luchas clasificatorias en torno al aborto: el caso de los médicos en hospitales públicos de México. Estudios Sociológicos 2006; 24:637-65.

10. Shellenberg KM, Moore AM, Bankole A, Juarez F, Omideyi AK, Palomino N, et al. Social stigma and disclosure about induced abortion: results from an exploratory study. Glob Public Health 2011; 6 Suppl 1:S111-25.

11. Sorhaindo AM, Juárez-Ramírez C, Díaz Olavarrieta C, Aldaz E, Mejía Piñeros MC, Garcia S. Qualitative evidence on abortion stigma from Mexico City and five states in Mexico. Women Health 2014; 54:622-40.

12. Lamas M. Mujeres, aborto e Iglesia católica. Revista de El Colegio de San Luis 2012; 2:42-67.

13. Calderón J, Alzamora de los Godos L. Influencia de las relaciones familiares sobre el aborto provocado en adolescentes. Rev Peru Med Exp Salud Pública 2006; 23:247-52.

14. Bermúdez C. Doctrina de la Iglesia y despenalización del aborto: algunas reflexiones. Pers Bioét 2005; 9:99-110.

15. Hanschmidt F, Linde K, Hilbert A, Riedel-Heller S, Kersting A. Abortion stigma: a systematic review. Perspect Sex Reprod Health 2016; 48:169-77. 
16. Morán J, Peñas M. ¿Defensores de la vida? ¿De cuál "vida"? Un análisis genealógico de la noción de "vida" sostenida por la jerarquía católica contra el aborto. Sex Salud Soc (Rio J.) 2013; 15:10-36.

17. Kimball R, Wissner M. Religion, poverty, and politics: their impact on women's reproductive health outcomes. Public Health Nurs 2015; 32:598-612.

18. García-Núñez N, Atienzo E, Dayananda I, Walker D. Legislación, conocimientos y actitudes de profesionales médicos en relación al aborto en México. Salud Colect 2013; 9:235-46.

19. Singer E. Lawful sinners: reproductive governance and moral agency around abortion in Mexico. Cult Med Psychiatry 2018; 42:11-31.

20. Barriera M, Ortiz S, Darromán R, Montoya M. Respuesta del estado psicológico en adolescentes con interrupción del embarazo. Rev Cuba Enferm 1999; 15:179-83.

21. Figueroa A, Aracena B, Reyes H, Lamadrid H. Factores asociados con la búsqueda del servicio de interrupción legal del embarazo en la ciudad de México. Salud Pública Méx 2010; 54:401-9.

22. Szulik D, Gogna M, Petracci M, Ramos S, Romero M. Anticoncepción y aborto en Argentina: perspectivas y obstetras y ginecólogos. Salud Púbica Méx 2008; 50:32-9.

23. Berger P, Luckmann T. La construcción social de la realidad. Buenos Aires: Amorrortu; 1991.

24. Thompson J. Ideología y cultura moderna. México DF: Universidad Autónoma Metropolitana; 1998.

25. Giddens A. La constitución de la sociedad, bases para la teoría de la estructuración. Buenos Aires: Amorrortu; 2003.
26. Medina A. Pueblos antiguos, ciudad diversa: una definición etnográfica de los pueblos originarios de la Ciudad de México. Anales de Antropología 2007; 41:10-52.

27. Instituto Nacional de Geografía e Informática. Principales resultados de la Encuesta Intercensal 2015. Ciudad de México: Instituto Nacional de Geografía e Informática; 2015.

28. Secretaría de Desarrollo Social, Gobierno de la Ciudad de México; Consejo de Evaluación para el Desarrollo Social de la Ciudad de México. Estudio del embarazo en adolescentes en la Ciudad de México desde un enfoque de género, 2005-2014. http://data.evalua.cdmx.gob. $\mathrm{mx} / \mathrm{docs} / \mathrm{gral} /$ Informe\%20Estudio\%20de\%20 Embarazo\%20de\%20Adolescente.pdf (accedido el 12/Jul/2018).

29. Figueroa J. Tres reflexiones sobre la sexualidad y los derechos humanos en el ámbito de la iglesia católica. Estudios Demográficos y Urbanos 2004; 57:639-86.

30. Moral J. Religión, significados y actitudes hacia la sexualidad: un enfoque psicosocial. Rey Colomb Psicol 2010; 19:45-59.

31. Núñez F. Los secretos para un feliz matrimonio: género y sexualidad en la segunda mitad del siglo XIX. Estudios de Historia Moderna y Contemporánea de México 2007; (33):5-32.

32. Harden A, Ogden J. Young women's experiences of arranging and having abortions. Sociol Health Illn 2001; 21:426-44.

33. Stern C. El embarazo en la adolescencia como problema público: una visión crítica. Salud Pública Méx 1997; 39:137-43.

34. Palomar C, Suárez M. Los entretelones de la maternidad: a la luz de las mujeres filicidas. Estudios Sociológicos 2007; 25:309-40. 


\section{Abstract}

In this article, we analyze beliefs and practices among young high school students who seek out or consider the possibility of terminating a pregnancy. We selected students from a public school located in a rural, peasant community in México City, México. This is a constructivist ethnographic study based on in-depth interviews with 15 sexually-active women aged between 18 and 24 years. The interviews were recorded with participants' authorization and informed consent. Results indicate that social stigmas persist which affect the dignity of women who have chosen to have an abortion. However, Catholic ideologies do not seem persuasive for participants who chose to carry the unwanted pregnancy to term. In any case, the absence of confidentiality in the clinics may lead young women to opt for clandestine spaces or for self-medication, usually based on natural medicine or abortive pills. Significantly, participants acknowledged that they did not use condoms and that they occasionally use oral contraceptives. The public health system in the community does not always guarantee confidentiality for legal terminations, for this reason participants do not consider it the first option for having an abortion. On the other hand, sexual education projects are indispensable for enabling young women to avoid unwanted pregnancies and to freely exercise their sexual and reproductive rights. Additionally, actions are needed for sensitizing and training education workers.

Abortion; Sexuality; Women; Students

\section{Resumo}

Neste trabalho são analisadas as crenças e práticas entre jovens estudantes do Ensino Médio que procuram ou consideram a possibilidade de interromper uma gravidez. Foram selecionados estudantes de uma escola pública localizada em una comunidade rural e camponesa da Cidade do México, México. Estudo etnográfico de caráter construtivista, baseado em entrevistas em profundidade a 15 mulheres entre 18 e 24 anos de idade, com vida sexual ativa. As entrevistas foram gravadas com autorização e com o consentimento informado dos participantes. Os resultados indicam que persistem estigmas sociais que afetam a dignidade das mulheres que escolheram abortar. Entretanto, as ideologias católicas no parecem ser persuasórias para que as informantes resolveram continuar com a gravidez indesejada. De qualquer forma, a ausência de confidencialidade nas clinicas pode levar as jovens a optar por espaços clandestinos o pela automedicação, normalmente baseada em medicina natural ou comprimidos abortivos. Foi significativo que as informantes reconheceram que não fizeram uso de preservativos e que eventualmente usam anticonceptivos orais. O sistema de saúde público na comunidade nem sempre garante o sigilo para interromper legalmente uma gravidez, por isso não é contemplado pelas jovens entrevistadas como a primeira opção para interromper a gestação. Por outro lado, e imprescindivel a consolidação de projetos educativos em sexualidade que permitam as jovens evitar gravidezes indesejadas e que possam ser livres para exercer plenamente seus direitos sexuais e reprodutivos. Além disso, é importante incluir ações relativas a sensibilização e capacitação de profissionais das instituições de ensino.

Aborto; Sexualidade; Mulheres; Estudantes
Recibido el 11/Mar/2018

Versión final presentada el 17/Oct/2018

Aprobado el 05/Nov/2018 